\title{
Evaluation of allelopathic competency of Lamium amplexicaule and identification of its allelopathic active substance
}

\author{
Chisato Sakamoto', Masahiko Suzuki ${ }^{1,2}$, Arihiro Iwasaki ${ }^{3}$, Kiyotake Suenaga ${ }^{3}$, Hisashi Kato-Noguchi ${ }^{1,2 *}$ \\ ${ }^{1}$ Department of Applied Biological Science, Faculty of Agriculture, Kagawa University, Miki, Kagawa 761-0795, Japan, ${ }^{2}$ The United Graduate \\ School of Agriculture Sciences, Ehime University, 3-5-7 Tarumi, Matsuyama, Ehime 790-8566, Japan, ${ }^{3}$ Department of Chemistry, Faculty of \\ Science and Technology, Keio University, Yokohama 223-8522, Japan
}

\section{A B S T R A C T}

\begin{abstract}
The weedy annual grass Lamium amplexicaule (L.) originated from the Mediterranean region, spreads quickly, and becomes naturalized in areas it invades. It was assumed that volatile phytotoxic substances are one of the invasive characteristics of $L$. amplexicaule. However, no volatile compound has been found. Therefore, we re-evaluated the allelopathic potential of $L$. amplexicaule and investigated the phytotoxic substances with allelopathic activity. An extract of L. amplexicaule inhibited the root and shoot growth of Lepidium sativum, Lactuca sativa, Arctium lappa, Lolium multiflorum Lam., Echinochloa crus-galli, and Vulpia myuros, which indicates that the extract has an allelopathic effect. The extract was purified using bioassay-guided chromatographic separations, and a phytotoxic substance with allelopathic activity was isolated and characterized as methyl caffeate. The compound significantly inhibited the root and shoot growth of $L$. sativum and L. multiflorum. The present results suggest that methyl caffeate may contribute to the allelopathic effect of the $L$. amplexicaule extracts and consequently, may be partly responsible for the invasive characteristics of the species.
\end{abstract}

Keywords: Allelopathy; Invasive weed; Growth inhibition; Lamium amplexicaule; Phytotoxicity

\section{INTRODUCTION}

Lamium amplexicaule (L.) is a weedy annual plant species of the Lamiaceae family that originated from the Mediterranean region and spread in Europe, Asia, and northern Africa. The species has adapted to quickly grow in crop fields, gardens, and pastures (USDA-NRCS, 2015; Stojanova et al., 2016). It competes with crops and other plant species and is categorized as an invasive alien weed in the USA and Canada (CABA, 2018).

Invasive plants possibly have physiological and ecological characteristics, such as high growth and reproduction rates, and phenotypic plasticity (Cappuccino and Arnason, 2006). The interactions of the invasive plants with natural enemies are also important. A strong defense capability against herbivores and pathogens may contribute to invasion (Keane and Crawley, 2002; Cappuccino and Carpenter, 2005). The interaction between invasive plants and native plants is also crucial. Several invasive plants contain unique compounds that are highly toxic to native plants (Callaway and Ridenour, 2004; Chengxu et al., 2011). Therefore, phytotoxicity or allelopathy or both are considered to be important for invasive plants to become naturalized in new habitats (Meiners et al., 2012).

The allelopathic activity of $L$. amplexicaule has been reported (Fujii et al., 1992). The species spreads quickly throughout wheat fields and suppresses crop production (Conley and Bradley, 2005). Jones et al. (2012) evaluated the volatile compounds in L. amplexicaule to determine if they contribute to its allelopathy. However, they could not find any volatile compounds that were responsible for the allelopathy. The objective of this study was to reevaluate the allelopathic potential of $L$. amplexicaule and to isolate and identify potential phytotoxic compounds with allelopathic activity.

\footnotetext{
*Corresponding author:

Hisashi Kato-Noguchi, Department of Applied Biological Science, Faculty of Agriculture, Kagawa University, Miki, Kagawa 761-0795, Japan. E-mail: hisashi@ag.kagawa-u.ac.jp
}

Received: 01 October 2018 ; Accepted: 11 January 2019 


\section{MATERIALS AND METHODS}

\section{Plant material}

Whole plants of Lamium amplexicaule (L.) were collected at Kumagaya, Japan in 2017 and kept at $-20^{\circ} \mathrm{C}$ until extraction. Dicotyledonous Lepidium sativum L., Lactuca sativa L., and Arctium lappa L. and monocotyledonous Lolium multiflorum Lam., Echinochloa crus-galli (L.) Beauv, and Vulpia myuros (L.) C. C. Gmel. were used as test plants for bioassay.

\section{Extraction and bioassay}

Whole plants of $L$. amplexicaule (170 $\mathrm{g}$ fresh weight) were cut into small pieces and extracted with $850 \mathrm{~mL}$ of $80 \%$ $(\mathrm{v} / \mathrm{v})$ aqueous methanol for two days. After filtration using filter paper (No. 2; Toyo Ltd., Tokyo, Japan), the residue was extracted again with $500 \mathrm{~mL}$ of methanol for two days and filtered. The two filtrates were combined and concentrated in vacuo at $40^{\circ} \mathrm{C}$.

An aliquot of the extract was added to a sheet of filter paper in a $2.8 \mathrm{~cm}$ Petri dish and dried in a fume hood. The filter paper was moistened with $0.6 \mathrm{~mL}$ of $0.05 \%(\mathrm{v} / \mathrm{v})$ aqueous solution of Tween 20 (polyoxyethylene sorbitan monolaurate; Nacalai, Kyoto, Japan). Ten seeds each of L. sativum, L sativa, and $A$. lappa, and 10 pre-germinated seedlings each of $V$. myuros, E. crus-galli, and L. multiflorum were placed onto filter paper in Petri dishes. L. sativum, L. sativa, L. multiflorum, E. crus-galli, and $V$. myuros were incubated in the dark at $25^{\circ} \mathrm{C}$ for $48 \mathrm{~h}$, and $A$. lappa was incubated in the dark at $25^{\circ} \mathrm{C}$ for $120 \mathrm{~h}$. After incubation, the root and shoot length of the test plants were measured. The bioassay concentrations of the extracts were $1,3,10,30,100,300$, and $1000 \mathrm{mg}$ fresh weight equivalent extract $\mathrm{mL}^{-1}$. Control test plants were incubated without the extracts. The bioassay was repeated two times using a randomized design with 10 plants for each determination. The concentrations required for $50 \%$ growth inhibition $\left(\mathrm{IC}_{50}\right.$ values) of the test plant roots and shoots were determined using a logistic regression function with Microsoft Excel based on the bioassay.

\section{Separation of the extract}

Whole plants of $L$. amplexicaule (5 $\mathrm{kg}$ fresh weight) were extracted with $18 \mathrm{~L}$ of $80 \%$ (v/v) aqueous methanol as described above. The extract was concentrated at $40^{\circ} \mathrm{C}$ to produce an aqueous solution. The aqueous solution was adjusted to $\mathrm{pH} 7.0$ with $1 \mathrm{M}$ phosphate buffer and partitioned three times with an equal volume of ethyl acetate. The ethyl acetate fraction was evaporated to dryness after drying over anhydrous $\mathrm{Na}_{2} \mathrm{SO}_{4}$, and then separated on a column of silica gel (40 g, silica gel 60, 70-230 mesh; Nacalai) with elution by 20 (fraction 1), 30 (fraction 2), 40 (fraction 3), 50 (fraction 4), 60 (fraction 5), 70 (fraction 6), and $80 \%$ (fraction 7) ethyl acetate in $n$-hexane $(\mathrm{v} / \mathrm{v}, 100 \mathrm{~mL}$ per step), ethyl acetate (fraction 8; $100 \mathrm{~mL}$ ), and methanol (fraction 9; $200 \mathrm{~mL}$ ). The biological activity of all the separated fractions was determined using a L. sativum bioassay as described above.

\section{Isolation of an active compound}

An active fraction obtained from the silica gel column was evaporated, and the residue was purified using a column of Sephadex LH-20 (40 g; GE Healthcare, Uppsala, Sweden) eluted with $20,30,40,50,60,70,80$, and $90 \%$ aqueous methanol (v/v, $100 \mathrm{~mL}$ per step) and methanol $(200 \mathrm{~mL})$. The fraction eluted with $60 \%$ aqueous methanol was active, and that active fraction was evaporated to dryness. The residue of the fraction was separated using flash chromatography (KeyChem-Flash, YMC-DospoPack AT ODS-25; YMC Co., Ltd.) eluted with 20, 30, 40, 50, 60, 70, and 80\% aqueous methanol (v/v, $150 \mathrm{~mL}$ per step) and methanol $(300 \mathrm{~mL})$. The active fraction was eluted with $40 \%$ aqueous methanol and evaporated to dryness. The residue of the fraction was finally separated using reverse-phase HPLC ( $\mu$ Bondshere $5 \mu$, $19 \times 150 \mathrm{~mm}$; Waters) eluted at a flow rate of $1.5 \mathrm{~mL} \mathrm{~min}^{-1}$ with $55 \%(\mathrm{v} / \mathrm{v})$ aqueous methanol and detected at $220 \mathrm{~nm}$. Activity was found in a peak fraction at $55 \mathrm{~min}$. The active compound was characterized using HRESI-MS, ${ }^{1} \mathrm{H}-\mathrm{NMR}$ $\left(400 \mathrm{MHz}, \mathrm{CDCl}_{3}\right)$, and ${ }^{13} \mathrm{C} \mathrm{NMR}\left(100 \mathrm{MHz}, \mathrm{CDCl}_{3}\right)$ spectra (TMS as internal standard). An active compound of $2.8 \mathrm{mg}$ was isolated from the extracts obtained from an extracted amount of $0.5 \mathrm{~kg}$ of $L$. amplexicaule.

\section{Bioassay for the isolated compound}

The isolated compound was dissolved in methanol and added to a sheet of filter paper (No. 2) in a $2.8 \mathrm{~cm}$ Petri dish. The methanol was evaporated in a fume hood. The biological activity of the compound was determined by bioassay using $L$. sativum and L. multiflorum as described above. L. sativum and L. multiflorum were used as the test plants because those plants had relatively high sensitivity to the extracts of L. amplexicaule among the dicotyledonous and the monocotyledonous test plants, respectively. The bioassay concentrations were $0.1,0.3,1,3$, and $10 \mathrm{mM}$. The bioassay was repeated two times using a completely randomized design with 10 plants for each determination.

\section{Statistical analysis}

Significant differences between treatment and control were examined using Welch's t-test (two sided) at $p<0.05$, 0.01 , or 0.001 .

\section{RESULTS AND DISCUSSION}

\section{Growth inhibitory activity of the extracts of L. amplexicaule}

The extracts of $L$. amplexicaule inhibited the root and shoot growth of $L$. sativum, L. sativa, A. lappa, L. multiflorum, E. crus-galli, and $V$. myuros. The level of inhibition increased 
with increasing concentrations of the extracts (Fig 1). The extracts of $L$. amplexicaule therefore had an allelopathic effect on both the dicotyledonous and monocotyledonous plants. These results suggest that $L$. amplexicaule may contain phytotoxic substances with allelopathic activity.

The $\mathrm{IC}_{50}$ values of the extracts on the test plants were in the range of $38.5-137 \mathrm{mg}$ fresh weight equivalent extract $\mathrm{mL}^{-1}$ for L. sativum, L. sativa, and A. lappa (dicotyledonous plants) and in the range of 126-937 $\mathrm{mg}$ fresh weight equivalent extract $\mathrm{mL}^{-1}$ for L. multiflorum, E. crus-galli, and $V$. myuros (monocotyledonous plants). Thus, the dicotyledonous plants were more sensitive to the extracts than the monocotyledonous plants (Table 1).

\section{Identification of the growth inhibitory substances in L. amplexicaule}

The extracts of $L$. amplexicaule were separated using a silica gel column, and the most active fraction was eluted with $60 \%$ ethyl acetate in $n$-hexane (Fig 2). The active fraction inhibited the $L$. sativum roots and shoots resulting in growth of 12.4 and $13.2 \%$, respectively, compared with the growth of the control plants. Therefore, the active fraction was further purified through chromatographic separation with the inhibitory activity determined by a bioassay using $L$. sativum, which is highly sensitive to the extracts of $L$. amplexicaule, and an active compound was isolated.

The active compound has the molecular formula of $\mathrm{C}_{10} \mathrm{H}_{8} \mathrm{O}_{4}$ as suggested by HRESI-MS at $\mathrm{m} / \mathrm{z} 192.9761$ $[\mathrm{M}-\mathrm{H}]^{-}$(calcd for $\left.\mathrm{C}_{10} \mathrm{H}_{9} \mathrm{O}_{4} 193.0501, \Delta=-383 \mathrm{ppm}\right) .{ }^{1} \mathrm{H}$ NMR $\left(400 \mathrm{MHz}, \mathrm{CD}_{3} \mathrm{OD}\right) \delta_{\mathrm{H}} 7.54(\mathrm{~d}, J=16.2 \mathrm{~Hz}, 1 \mathrm{H}$, H-7), 7.03 (d, $J=2.1 \mathrm{~Hz}, 1 \mathrm{H}, \mathrm{H}-2), 6.94$ (dd, $J=8.4$, $2.1 \mathrm{~Hz}, 1 \mathrm{H}, \mathrm{H}-6), 6.77$ (d, J = 8.4 Hz, $1 \mathrm{H}, \mathrm{H}-5), 6.26$ $(\mathrm{d}, J=16.2 \mathrm{~Hz}, 1 \mathrm{H}, \mathrm{H}-8), 3.76$ (s, $3 \mathrm{H}, \mathrm{H}-10) ;{ }^{13} \mathrm{C}$ NMR (100 MHz, (CD $\left.{ }_{3} \mathrm{OD}\right) \delta_{\mathrm{C}} 169.8$ (C-9), 149.6 (C-4), 147.0

Table 1. $I C_{50}$ values (concentrations required for $50 \%$ growth inhibition) of the extracts of $L$. amplexicaule on $L$. sativum, L. sativa, A. lappa, L. multiflorum, E. crus-galli, and V. myuros

\begin{tabular}{lll}
\hline Test plant & \multicolumn{2}{c}{$\begin{array}{c}\mathrm{IC}_{50} \text { (mg fresh weight } \\
\text { equivalent extract } \mathrm{mL}^{-1} \text { ) }\end{array}$} \\
\cline { 2 - 3 } & Shoot & Root \\
\hline Dicotyledonous & & \\
L. sativum & 46.9 & 52.6 \\
L. sativa & 67.9 & 38.5 \\
A. lappa & 137 & 93.3 \\
Monocotyledonous & & \\
L. multiflorum & 366 & 126 \\
E. crus-galli & 937 & 323 \\
V. myuros & 506 & 131 \\
\hline
\end{tabular}

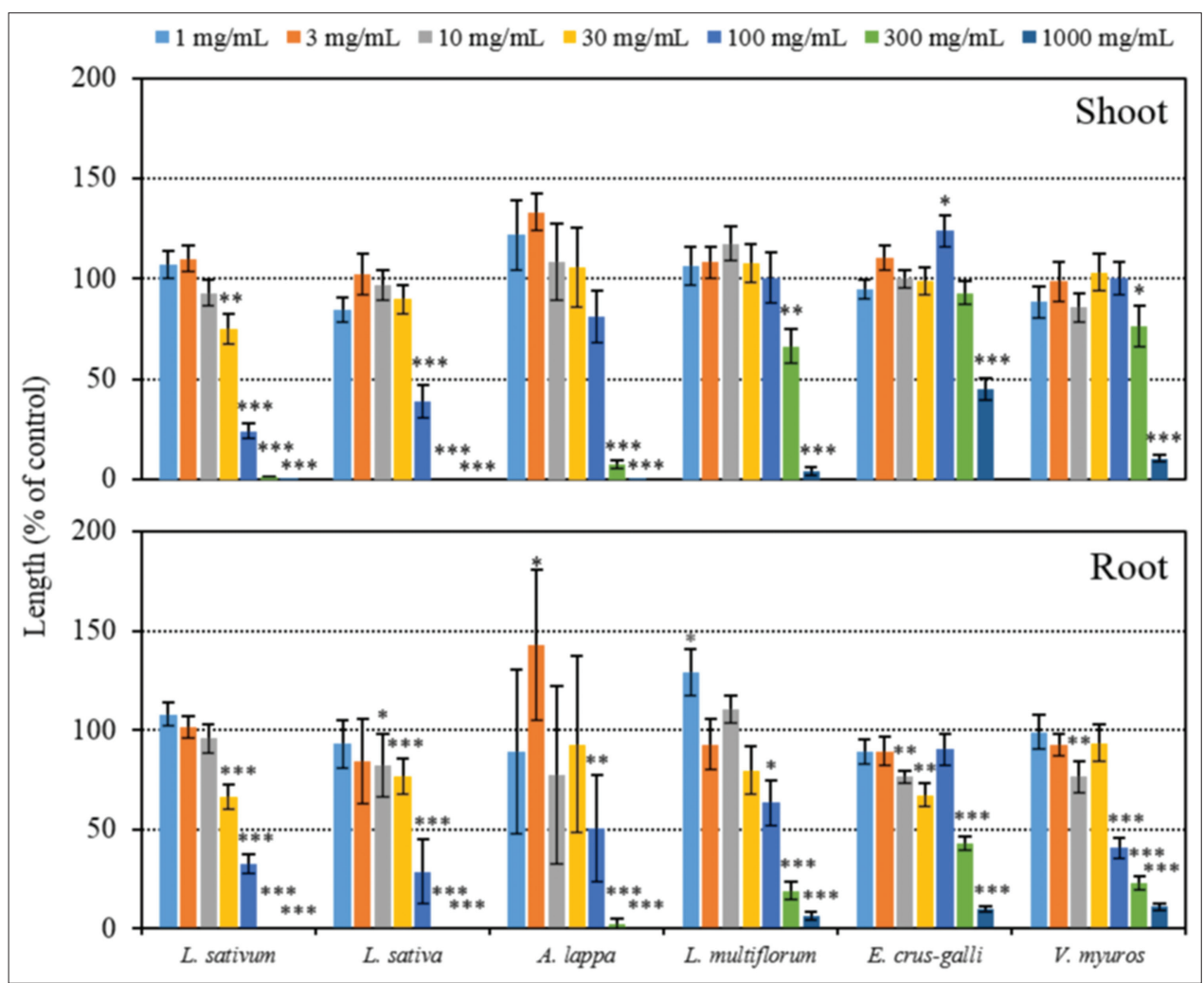

Fig 1. Effect of the extracts of L. amplexicaule on the root and shoot growth of L. sativum, L. sativa, A. lappa, L. multiflorum, E. crus-galli, and $V$. myuros. Concentrations of the tested samples corresponded to the extracts obtained from 1, 3, 10, 30, 100, 300, and 1000 mg fresh weight of $L$. amplexicaule per $\mathrm{mL}$. Means $\pm \mathrm{SE}$ from 2 independent experiments with 10 plants for each determination are shown. Asterisks indicate significant difference between control and treatment: ${ }^{*}, p<0.05,{ }^{* *}, p<0.01,{ }^{* * *}, p<0.001$. 
(C-3), 146.8 (C-7), 127.6 (C-1), 122.9 (C-6), 116.5 (C-5), 115.1 (C-8), 114.8 (C-2), 52.0 (C-10). The active compound was identified as methyl caffeate (Fig 3) by comparing with previous data (Zhu et al., 2010; Prevost et al., 2013). Although methyl caffeate has been isolated from several plant species (Xiang et al., 2011; Balachadran et al., 2015; Wang et al., 2015), the present report is the first on methyl caffeate as a phytotoxic substance in $L$. amplexicaule.

\section{Biological activity of the isolated substances}

Methyl caffeate significantly inhibited the root and shoot growth of L. sativum and L. multiflorum at concentrations greater than $1 \mathrm{mM}$ (Fig 4 and 5). The $\mathrm{IC}_{50}$ values of methyl caffeate on the roots and shoots of $L$. sativum were 2.0 and $1.4 \mathrm{mM}$, respectively, and on the roots and shoots of L. multiflorum were 1.1 and $2.5 \mathrm{mM}$, respectively. The compound has also been reported to possess anticancer activity against human breast cancer cells (Bailly et al., 2013), antimalarial activity against a Plasmodium berghei strain (Alson et al., 2018), antihyperglycemic activity in diabetic

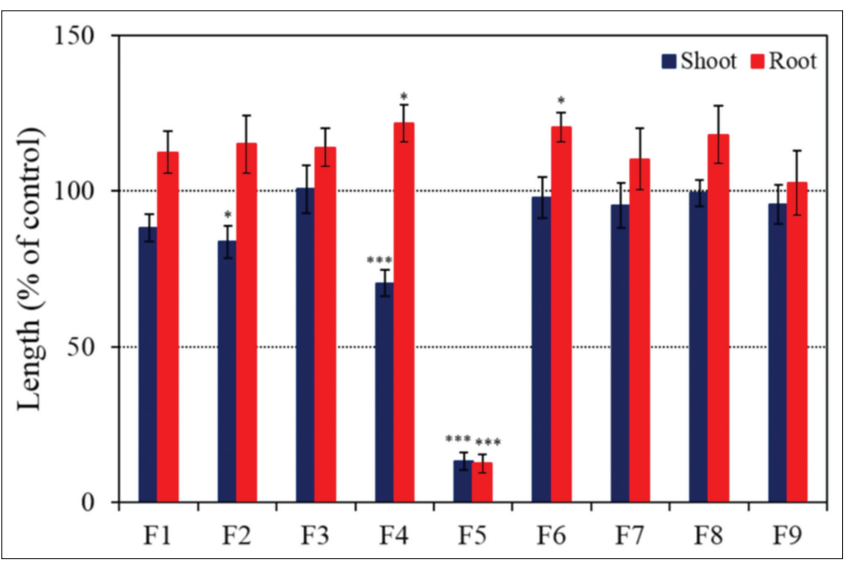

Fig 2. Effect of the fractions obtained from silica gel column chromatography of the $L$. amplexicaule extracts on the root and shoot growth of $L$. sativum. The length of the roots and shoots of the $L$. sativum seedlings was determined after $48 \mathrm{~h}$ of incubation in the dark at $25^{\circ} \mathrm{C}$. The concentration of the tested samples corresponded to the extract obtained from $1000 \mathrm{mg}$ fresh weight of $L$. amplexicaule per $\mathrm{mL}$. Means $\pm \mathrm{SE}$ from 2 independent experiments with 10 plants for each determination are shown. Asterisks indicate significant difference between control and treatment: ${ }^{*}, p<0.05,{ }^{* * *}, p<0.001$.

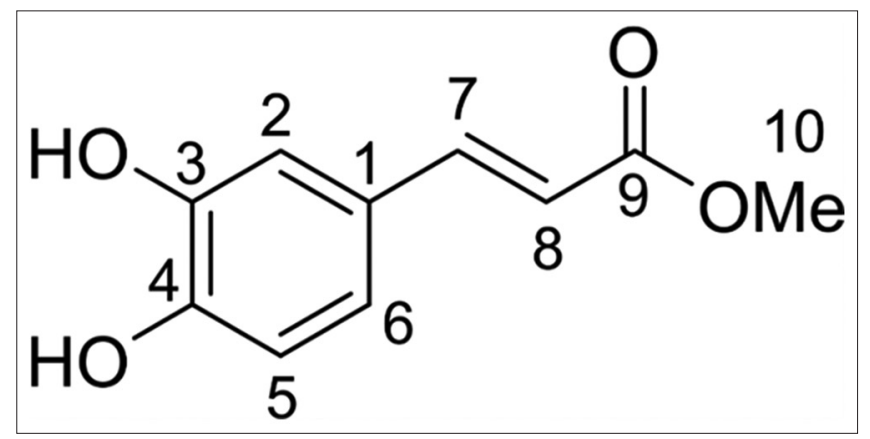

Fig 3. Chemical structure of methyl caffeate. rats (Gandhi et al., 2011), and antioxidant activities under in vitro conditions (Wang et al., 2015). Methyl caffeate is a methyl ester of caffeic acid, which has also been reported to have biological activity (Fernandez et al., 2009; Scognamiglio et al., 2012). However, the activity of methyl caffeate was 2.9-fold greater than that of caffeic acid (Alson et al., 2018), which suggests that the methoxy group at the $\mathrm{C}-10$ position in caffeic acid may be important for the activity.

Phytotoxic active substances in plants are released into the soil by decomposition of plant residues and exudates from living plant tissues, and act as allelopathic substances. Those substances can inhibit seed germination and plant growth (Bais et al., 2006; Bonanomi et al., 2006; Belz, 2007). Methyl caffeate in L. amplexicaule may also be released into the soil in the same manner and act as an allelopathic substance.

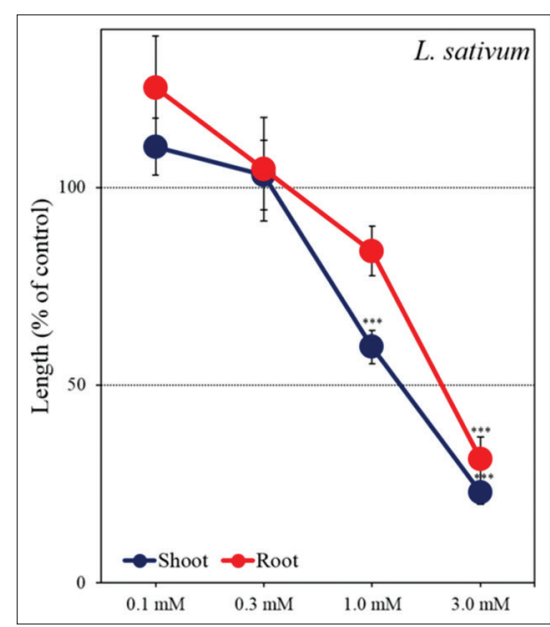

Fig 4. Effect of methyl caffeate on the root and shoot growth of L. sativum. Means \pm SE from 2 independent experiments with 10 seedlings for each determination are shown. ${ }^{* * *}, p<0.001$.

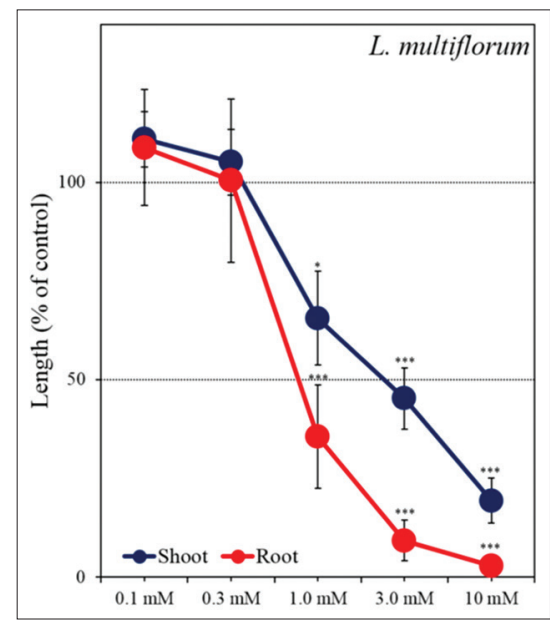

Fig 5. Effect of methyl caffeate on the root and shoot growth of L. multiflorum. Means \pm SE from 2 independent experiments with 10 seedlings for each determination are shown. ${ }^{*}, p<0.05,{ }^{* * *}, p<0.001$. 
The weedy grass $L$. amplexicaule strongly competes with other plants and is categorized as an invasive alien weed (CABA, 2018). Phytotoxicity and allelopathy are considered to be important for invasion of new habitats (Meiners et al., 2012). It has been reported that $L$. amplexicaule possesses allelopathic potential (Fujii et al., 1992). However, volatile compounds involved in the allelopathy could not be found Jones et al., 2012). The present research re-evaluated the allelopathic activity of $L$. amplexicaule and isolated methyl caffeate, which showed phytotoxic activity. The phytotoxic compound may contribute to the invasive characteristics of $L$. amplexicaule.

\section{CONCLUSION}

The extracts of $L$. amplexicaule show allelopathic activity. The extract was purified using bioassay-guided chromatographic separations, and a phytotoxic substance with allelopathic activity was isolated and characterized as methyl caffeate. The compound significantly inhibited the growth of L. sativum and L. multiflorum. These results suggest that methyl caffeate may contribute to the allelopathic activity of the $L$. amplexicaule extracts and consequently, may be partly responsible for the invasive characteristics of $L$ amplexicaule. However, further experiments are required to clarify the release route of this compound into the environment.

\section{Authors' contributions}

Chisato Sakamoto: ran the experiments and data analysis. Masahiko Suzuki: technical support for the experiments. Arihiro Iwasakiand Kiyotake Suenaga: determination of chemical structures of the compounds. Hisashi KatoNoguchi: responsible for experimental design and results interpretation coordinated data analysis and wrote the paper.

\section{REFERENCES}

Alson, S.G., O. Jansen, E. Cieckiewicz,H. Rakotoarimanana, H. Rafatro, G. Degotte, P. Francotte and M. Frederich. 2018. In-vitro and in-vivo antimalarial activity of caffeic acid and some of its derivatives. J. Pharm. Pharmacol. 70: 1349-1356.

Bailly, F., R. A. Toillon, O. Tomavo, N. Jouy, H. Hondermarck and P. Cotelle. 2013. Antiproliferative and apoptotic effects of the oxidative dimerization product of methyl caffeate on human breast cancer cells. Bioorg. Med. Chem. Lett. 23: 574-578.

Bais, H. P., T. L. Weir, L. G. Perry, S. Gilroy and J. M. Vivanco. 2006. The role of root exudates in rhizosphere interactions with plants and other organisms. Ann. Rev. Plant Biol. 57: 233-266.

Balachadran, C., N. Emi, Y. Arun, Y. Yamamoto, B. Ahilan, B. Sangeetha, V. Duraipandiyan, Y. Inaguma, A. Okamoto, S. Ignacimuthu, N. A. Al-Dhadi and P. T. Perumal. 2015. In vitro anticancer activity of methyl caffeate isolated from Solanum torvum Swartz. Fruit. Chem. Biol. Interact. 242: 81-90.

Belz, R. G. 2007 Allelopathy in crop/weed interactions-an update. Pest Manag. Sci. 63: 308-326.

Bonanomi, G., M. G. Sicurezza, S. Caporaso, A. Esposito and S. Mazzoleni. 2006. Phytotoxicity dynamics of decaying plant materials. New Phytol. Trust. 169: 571-578.

CABA. 2018. Invasive Species Compendium. Available from: https:// www.cabi.org/isc/datasheet/29728.

Callaway, R. M. and W. M. Ridenour. 2004. Novel weapons: Invasive success and the evolution of increased competitive ability. Front. Ecol. Environ. 2: 419-426.

Cappuccino, N. and D. Carpenter. 2005. Invasive exotic plants suffer less herbivory than non-invasive plants. Biol. Lett. 1: 435-458.

Cappuccino, N. and J. T. Arnason. 2006. Novel chemistry of invasive exotic plants. Biol. Lett. 2: 189-193.

Chengxu, W., Z. Mingxing, C. Xuhui and Q. Bo. 2011. Review on allelopathy of exotic invasive plants. Procedia Eng. 18: 240-246.

Conley, S. P. and K. W. Bradley. 2005. Wheat (Triticum aestivum) yield response to henbit (Lamium amplexicaule) interference and simulated winterkill. Weed Technol. 19: 902-906.

Fernandez, C., Y. Monnier, E. Ormeño, V. Baldy, S. Greff, V. Pasqualini, J. P. Mévy and A. Bousquet-Mélou. 2009. Variations in allelochemical composition of leachates of different organs and maturity stages of Pinus halepensis. J. Chem. Ecol. 35: 970-979.

Fujii, Y., T. Shibuya and T. Yasuda. 1992. Allelopathy of velvet bean: Its discrimination and identification of L-DOPA as a candidate of allelopathic substances. Jpn. Agric. Res. Q. 25: 238-247.

Gandhi, G. R., S. Ignacimuthu, M. G. Paulraj and P. Sasikumar. 2011. Antihyperglycemic activity and antidiabetic effect of methyl caffeate isolated from Solanum torvum Swartz. Fruit in streptozotocin induced diabetic rats. Eur. J. Pharmacol. 670: 623-631.

Jones, C. D., K. E. Woods, N. William and W. N. Setzer. 2012. A chemical ecological investigation of the allelopathic potential of Lamium amplexicaule and Lamium purpureum. Open J. Ecol. 2: 167-177.

Keane, R. M. and M. L. Crawley. 2002. Exotic plant invasions and the enemy release hypothesis. Trend Ecol. Evol. 17: 164-170.

Meiners, S. J., C. H. Kong, L. M. Ladwig, N. L. Pisula and K. A. Lang. 2012. Developing an ecological context for allelopathy. Plant Ecol. 213: 1861-1867.

Prevost, M. S., S. Delarue-Cochin, J. Marteaux, C. Colas, C. van Renterghem, A. Blondel, T. Malliavin, P. J. Corringer and D. Joseph. 2013. Identification of cinnamic acid derivatives as novel antagonist of the prokaryotic proton-gated ion channel GLIC. J. Med. Chem. 56: 4619-4630.

Scognamiglio, M., A. Esposito, B. D’Abrosca, S. Pacifico, V. Fiumano, N. Tsafantakis, P. Monaco and A. Fiorentino. 2012. Isolation, distribution and allelopathic effect of caffeic acid derivatives from Bellis perennis L. Biochem. Syst. Ecol. 43: 108-113.

Stojanova, B., S. Maurice and P. O. Cheptou. 2016. Is plasticity across seasons adaptive in the annual cleistogamous plant Lamium amplexicaule? Ann. Bot. 17: 681-691.

USDA-NRCS. 2015. The Plants Database. Available from: http:// www.plants.usda.gov/core/profile?symbol=LAAM.

Wang, L., J. Guo, J. Zhang, J. Peng, T. Liu and Z. Xin. 2015. Isolation, identification and antioxidant activity of bound phenolic compounds present in rice bran. Food Chem. 171: 40-49.

Xiang, M., S. Hanwen, H. Jinyue and Y. Yunjin. 2011. Isolation, identification and determination of methyl caffeate, ethyl caffeate and other phenolic compounds from Polygonum amplexicaule var. sinense. J. Med. Plants Res. 5: 1685-1691.

Zhu, Y., L. X. Zhang, Y. Zhao and G. D. Huang. 2010. Unusual sesquiterpene lactones with a new carbon skeleton and new acetylenes from Ajania przewalskii. Food Chem. 118: 228-238. 